\title{
Sales and operations planning: learnings from 15 Brazilian companies*
}

\author{
Marcelo Xavier Seeling¹, Carlos Eduardo Panitz², Ricardo Augusto Cassel² \\ ${ }^{1}$ Pontifícia Universidade Católica do Rio de Janeiro - PUC-Rio, Rio de Janeiro, RJ, Brazil. \\ Universidade Federal do Rio Grande do Sul - UFRGS, Porto Alegre, RS, Brazil.
}

How to cite: Seeling, M.X., Panitz, C.E., and Cassel, R.A. (2021), “Sales and operations planning: learnings from 15 Brazilian companies", Brazilian Journal of Operations \& Production Management, Vol. 18, No. 3, e20211135. https://doi.org/10.14488/BJOPM.2021.019

\section{ABSTRACT}

Goal: The goal of this paper is to investigate 15 Brazilian companies, which execute S\&OP cycles periodically, in order to characterize the processes implemented and discuss challenges and improvement opportunities.

Design / Methodology / Approach: Initially, a multiple-case study approach is applied embracing 15 Brazilian companies. Then, a survey is conducted in the same organizations to deepen the investigation. Two recognized S\&OP frameworks from the literature are used to structure the research.

Results: Some of the main research findings include: some companies consider "Data Gathering" a normal task and no longer a S\&OP cycle step; some organizations include a new step one named "Portfolio Management", preceding "Demand Planning" to leverage step two's outcomes; there are improvement opportunities identified in "Pre-meeting" and "Executive Meeting" steps regarding capacity to simulate different scenarios from a financial perspective; and most of the studied companies do not adopt a S\&OP software facing limitations to manage information and perform what-if analysis.

Limitations of the investigation: Only companies located in Brazil are investigated.

Practical implications: The study provides useful information for practitioners on the characterization of the S\&OP process, implementation challenges, and improvement opportunities.

Originality / Value: The paper applies different research methods (multiple-case study and survey) and two recognized frameworks from the literature in the study of the S\&OP process performed by 15 companies, providing a broad characterization of the processes implemented and valuable findings about challenges and improvement opportunities. Although all the researched companies are Brazilian, evidences indicate the results are generalizable.

Keywords: S\&OP; Supply Chain; Planning Process; Multiple-Case Study.

\section{INTRODUCTION}

S\&OP has been considered for decades a recognized planning process within the context of supply chain management and therefore adopted by organizations from different industries worldwide (Lapide, 2004a; Bower, 2015; Noroozi and Wikner, 2017). It is a process

*This article is from the XXVI International Conference on Industrial Engineering and Operations Management (IJCIEOM) and was invited to be published in the September/2021 Special Issue of the Brazilian Journal of Operations \& Production Management, due to its relevance and contribution to the field.

Financial support: None.

Conflict of interest: The authors have no conflict of interest to declare.

Corresponding author: seeling@puc-rio.br

Received: 23 Dec 2020

Approved: 4 Jan 2021.

Editor: João Reis 
performed periodically that balances the company's demand and its supply resources. Several business functions' plans (e.g. sales, marketing, operations, and finance) are reconciled along the S\&OP cycle converging to a single company plan, which is aligned with organization's strategic plan (Feng et al., 2013; Tuomikangas and Kaipia, 2014, Goh and Eldridge, 2019). There are sound indications that S\&OP, under some implementation conditions, contributes to improve the organization's supply chain results (Thomé et al., 2014a; García-Villarreal et al., 2019) and overall firm performance (Thomé et al., 2012b).

Even though all the attention given to $\mathrm{S} \& O P$, which is observed in the growing research body about the theme (Tuomikangas and Kaipia, 2014; Danese et al., 2017; Kristensen and Jonsson, 2018), there are gaps still to be explored, resulting in opportunities for empirical studies (Kjellsdotter Ivert et al. 2015a; Goh and Eldridge, 2015) such as the lack of a complete characterization of the S\&OP process (Pedroso et al., 2016; Scavarda et al., 2017) and case studies and surveys with practitioners. Moreover, changes in the business environment and new technologies have been shaping new challenges and opportunities to be addressed by the S\&OP process. This leads to the following research questions (RQs).

RQ1: How can the S\&OP process be characterized?

RQ2: What challenges and improvement opportunities can be identified in its execution?

Therefore, the goal of this paper is to investigate 15 Brazilian companies from different business segments, which execute S\&OP cycles periodically, comprising two foci: 1) to characterize the S\&OP implementations in these companies; and 2) to present and discuss challenges and improvement opportunities in the S\&OP process of the studied companies.

All studied companies are located in Brazil, which could be considered a limitation of the study. However, the organizations are mostly large and complex enterprises, comparable to similar companies of the same business segments in other geographies indicating the possibility of generalization of results. The Brazilian macro context (e.g., economy, business environment, among other factors) and its potential impact on the companies is not part of this research but it never influenced the analysis performed.

Two recognized S\&OP frameworks from the literature are used to describe and to support the analysis of the companies' implemented process similarly to Seeling et al. (2019): Thomé et al.'s (2012a) "Integrative Model" and Wallace and Stahl's (2006) "Five-step Model".

The paper is structured as follows. This introduction opens the paper offering the theme context, its relevance, the RQs, the paper goal, and the limitations of the study. The second section provides a theoretical background on S\&OP. The third section depicts the research method adopted. The fourth section presents the results, discusses them and offers the paper's main findings. The main conclusions of this research and opportunities for future complementary studies close the paper.

\section{THEORETICAL BACKGROUND}

S\&OP is a business process (Grimson and Pyke, 2007; Goh and Eldridge, 2015) performed routinely (Lapide, 2004b; Feng et al., 2008; Thomé et al., 2012a) and a tactic cycle (Wallace and Stahl, 2006; Lapide, 2011; Wang et al., 2012) that provides horizontal alignment, integrating different business functions' plans into one set of reconciled plans (Cox and Blackstone, 2002; Wallace and Stahl, 2006; Thomé et al., 2012a; Kristensen and Jonsson, 2018). It is usually run within the company's boundaries but mature implementations may embrace key suppliers and customers in the activities (Lapide, 2004b; Feng et al., 2008; Baumann, 2010). S\&OP balances demand and supply (Lapide, 2004b; Wallace and Stahl, 2006; Feng et al., 2013), considering the company's operational and financial capabilities (Feng et al., 2008).

It usually handles the demand forecast of the current portfolio at an aggregate level and segmented by channel. Even though, there are some companies that run their forecast process at stock keeping unit (SKU) level. An 18-month planning horizon is typical (Grimson and Pyke, 2007; Thomé et al., 2012a) but companies may choose other time windows, accordingly to their specific needs (Grimson and Pyke, 2007) such as coinciding with strategic 
planning and budgeting periodicities, considering supply chain cumulative lead times, among others.

When S\&OP is properly implemented, it may generate benefits to the enterprise (Thomé et al., 2012a; Noroozi and Wikner, 2017; Kristensen and Jonsson, 2018) contributing to increase revenue, reduce costs, maximize profit, improve service to customers, increase forecast accuracy, optimize inventory, and maximize asset utilization (Thomé et al., 2012a). A successful S\&OP process implementation assures execution is aligned with business strategy and checks key performance indicators (KPI) at each cycle to promote improvements (Cox and Blackstone, 2002).

S\&OP is usually a five-step monthly cycle (Wallace and Stahl, 2006; Grimson and Pyke, 2007; Thomé et al., 2012a; Kjellsdotter Ivert et al., 2015a). The steps are depicted as follows, according to Wallace and Stahl (2006). Step 1 is Data Gathering, when different product, operational and financial information, among others, are uploaded in the company's Enterprise Resource Planning (ERP) system and made available for Sales and Marketing to support the demand plan construction. Step 2 is Demand Planning, which includes portfolio analysis, sales forecast and discussions around new product launches and trade-marketing initiatives. Step 3 is Supply Planning, when the unrestricted Demand Plan, received from previous step, is confronted with the capacity constraints to build a feasible Supply Plan. Step 4 is Pre-meeting, when representatives from the different business functions involved in the cycle discuss the demand-supply gaps and work collaboratively to mitigate them. The agreed plan proposal with financial analysis and the pending issues that need top executives' (e.g., directors and president) decisions are taken to the step 5, the Executive Meeting. The S\&OP Plan is approved in the Executive Meeting and projects and KPIs are reviewed.

The S\&OP framework developed by Thomé et al. (2012a), presented in Figure 1, is applied to verify the presence of the S\&OP key elements. Its main building blocks and dimensions are used to structure the analysis of the collected data in this paper. The "business plan" and its deployment, the "corporate strategic plan", constitute the highest level of the company's strategy. "Context" refers to the organization's internal operational environment and its external market environment. "Inputs" include all the information used by the S\&OP process (e.g., business functions' plans, costs, operational capabilities, inventory data, budget). Four process dimensions compose "Structure and Processes": meeting and collaboration, organization, information technology and metrics. "Outcomes" include the integration of marketing, sales, operations and finance plans into one reconciled set of plans. The expected main result from the process is profit optimization (Grimson and Pyke, 2007; Thomé et al., 2012a) even though there are objectives related to improving the supply chain as well. "Operations" encompass enterprise's core business activities such as manufacturing and logistics, among others.

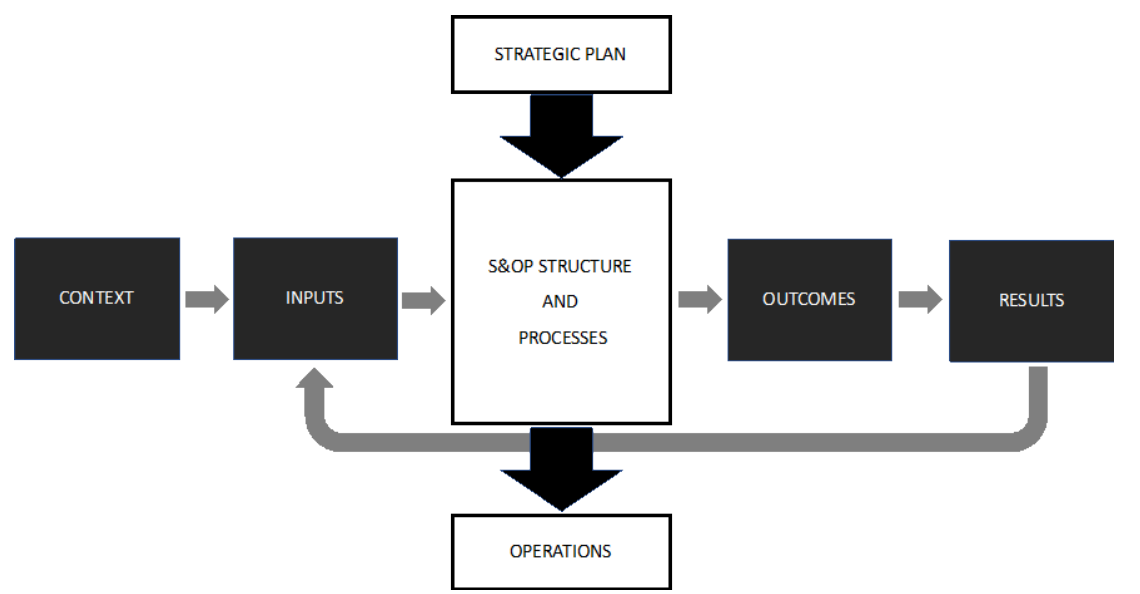

Figure 1. The S\&OP Framework

Source: Adapted from Thomé et al. (2012a). 


\section{RESEARCH METHOD}

The paper applies different research methods together to strengthen the results obtained. The research is initially conducted through a multiple-case study (Yin, 2009) in 15 Brazilian companies from different business segments. The multiple-case study was performed through interviews with key executives at their workplaces, site visits and analysis of internal documents regarding the S\&OP cycle such as meeting minutes, presentations, various reports, KPI dashboards, S\&OP plans, among others. In the sequence, a survey (Gil, 2008) is applied to broaden the number of participants from the studied organizations, deepening the investigation.

The unit of analysis is the S\&OP process, which was implemented and is run periodically in these organizations. Two research questions and the paper goal structure the research.

All organizations in the sample are Brazilian companies, mostly large and complex enterprises, many are subsidiaries of multinational corporations, with many suppliers, large portfolio of products, spread client basis and high revenues, typical candidates to benefit from a S\&OP implementation (Thomé et al., 2014b). In addition, all these companies have run a S\&OP cycle for a while, similar to Wallace and Stahl's (2006) five-step model, although with different levels of maturity. Therefore, their characteristics make them comparable and similar to large organizations of the same business segments worldwide, conferring representativeness to the chosen sample, and indicating the possibility of generalization of results.

Relevant literature about the S\&OP theme was reviewed to base the analysis of this research.

This paper applies Thomé et al.'s (2012a) framework to characterize the S\&OP process running in the companies, similarly to Seeling et al. (2019). Kristensen and Jonsson (2018) called it a well-known "integrative S\&OP framework". It describes S\&OP as a whole and not as a partial process (Kjellsdotter Ivert et al., 2015b), being generalizable and not restricted to specific contexts (Noroozi and Wikner, 2017). It incorporates the main building blocks of S\&OP and contemplates vertical and horizontal alignments in a systematic and holistic manner (Kjellsdotter Ivert et al., 2015a). It is consistent with Kathuria et al. (2007), where vertical alignment bridges strategy to operations, while horizontal alignment refers to cross-functional and intra-functional integration.

Additionally, this paper uses Wallace and Stahl's (2006) five-step model as a reference to describe the standard S\&OP cycle-steps and then to compare it to the studied companies' cycles. Many authors indicate that S\&OP is usually performed in five steps (e.g., Lapide, 2004a; Grimson and Pyke, 2007; Thomé et al., 2012a; Danese et al., 2017; Seeling et al., 2019; among others). Wallace and Stahl's (2006) model depicts these five steps in accordance with the literature on the theme and has based many process implementations thus being widely used. It is also the reference for the cycle-steps run in the majority of the 15 companies researched in this paper.

During the conduction of the multiple-case studies, interviews were performed with 25 professionals from the 15 companies, following a fieldwork protocol described in Appendix 1. A semi-structured questionnaire designed for the purpose was applied to guide the interviews (Yin, 2009) and complemented by open-ended questions to expand and clarify the information obtained. The interviews lasted at least one hour and were performed at the executive's workplaces. In some cases, due to the good access the researchers had to the companies, more visits were scheduled therefore allowing an in-depth assessment. After the face-to-face interviews, a survey with four questions was carried out with 30 professionals from the same companies to expand the exploration of topics related to the S\&OP implementation in the organizations and the opportunities for improvement identified in the process. The questions are presented one by one together with their respective result analysis in the section 4.3. Faceto-face interviews and the survey were conducted with analysts, supervisors and managers involved in the S\&OP process. Table 1 presents the companies and the professionals involved in this research. 
Table 1. Companies and research respondents

\begin{tabular}{|c|c|c|c|c|c|c|c|c|c|}
\hline & & $\begin{array}{c}\text { Intervi } \\
\text { ew }\end{array}$ & Survey & & & & & & \\
\hline $\begin{array}{l}\text { Comp } \\
\text { any }\end{array}$ & Industry & $\begin{array}{c}\text { Analys } \\
t\end{array}$ & $\begin{array}{l}\text { Supervi } \\
\text { sor }\end{array}$ & $\begin{array}{l}\text { Mana } \\
\text { ger }\end{array}$ & & $\begin{array}{l}\text { Anal } \\
\text { yst }\end{array}$ & $\begin{array}{l}\text { Supervi } \\
\text { sor }\end{array}$ & $\begin{array}{l}\text { Mana } \\
\text { ger }\end{array}$ & \\
\hline A & Telecom & & & 1 & & & & 1 & \\
\hline B & Auto-parts & 1 & & 1 & & 1 & 1 & 1 & \\
\hline C & $\begin{array}{c}\text { Transportation } \\
\text { equipment }\end{array}$ & 1 & 1 & 1 & & 1 & 1 & 1 & \\
\hline D & Consumer goods & 1 & 1 & 1 & & 1 & 1 & 1 & \\
\hline $\mathbf{E}$ & $\begin{array}{l}\text { Agricultural } \\
\text { machinery }\end{array}$ & & & 1 & & & 1 & 1 & \\
\hline $\mathbf{F}$ & Consumer goods & & 1 & 1 & & 1 & 1 & 1 & \\
\hline G & Consumer goods & 1 & 1 & 1 & & 1 & 1 & 1 & \\
\hline $\mathbf{H}$ & Foods and Beverages & & & 1 & & & & 1 & \\
\hline I & Minning & & & 1 & & & & 1 & \\
\hline J & Consumer goods & 1 & 1 & 1 & & 1 & 1 & & \\
\hline $\mathbf{K}$ & $\begin{array}{c}\text { Apparel and } \\
\text { footwear industry }\end{array}$ & & & & & & 1 & & \\
\hline $\mathbf{L}$ & Pulp and paper & & & & & & 1 & & \\
\hline M & Textiles & & & & & & & 1 & \\
\hline $\mathbf{N}$ & Wholesale & 1 & & 1 & & 1 & & 1 & \\
\hline \multirow[t]{2}{*}{0} & Tools & 1 & 1 & 1 & & 1 & 1 & 1 & \\
\hline & Total & 7 & 6 & 12 & $\begin{array}{l}2 \\
5\end{array}$ & 8 & 10 & 12 & $\begin{array}{l}3 \\
0\end{array}$ \\
\hline
\end{tabular}

Source: the authors themselves.

Field observations, answers from interviews, internal documents and public data about the companies were analyzed and validity checks and triangulations were performed by the researchers to ensure information reliability, correct interpretation and to assess the consistency of the results and limitations of the study.

\section{RESULTS AND DISCUSSIONS}

This section offers the studied companies' S\&OP process characterization using Thomé et al. (2012a) framework, similarly to Seeling et al. (2019). The main building blocks of the S\&OP framework are utilized to describe the process: context, inputs, structure and processes, outcomes and results. Additionally, Wallace and Stahl (2006) Five-step model is compared to companies' S\&OP cycle-steps. Section 4.1 and 4.2 address the RQ1. The results and findings from the interviews and the survey are then presented and discussed. Section 4.1, 4.2 and mainly 4.3 address the RQ2.

\subsection{Companies' S\&OP characterization using Thomé et al. (2012a) framework}

\subsubsection{Context}

The research was conducted with fifteen Brazilian companies. Fourteen organizations are manufacturing companies and one is a wholesaler. The companies' annual revenues range from US\$17 Million up to US\$8.5 Billion. Five companies (33\%) have more than 1000 SKUs in 
the portfolio, eight companies (53\%) have from 100 to 1000 SKUs, one company (7\%) has less than 100 SKU's (company I) and one company (7\%) has more than 10000 SKUs (company N). It is relevant to notice that the companies that manufacture products with short shelf life or products with short life cycle (e.g., consumer goods and food and beverages) have portfolios smaller than 1000 SKU's. Thirteen companies adopt make-to-stock strategies (MTS). The transportation equipment manufacturer and the agricultural machinery manufacturer (companies C and E) adopt a make-to-order strategy in general but they produce and keep inventory of a few SKUs with high demand. Table 2 presents some variables that characterize the companies' individual contexts.

Table 2. Context parameters

\begin{tabular}{cclc}
\hline $\begin{array}{c}\text { Compan } \\
\text { y }\end{array}$ & Industry & $\begin{array}{c}\text { Manufacturing } \\
\text { Strategy }\end{array}$ & $\begin{array}{c}\text { Revenues (US\$ } \\
\text { Million) }\end{array}$ \\
\hline A & $\begin{array}{c}\text { Apparel and footwear } \\
\text { industry }\end{array}$ & Make to Stock & 81 \\
\hline B & Agricultural machinery & Make-to-order & 952 \\
\hline C & Auto-parts & Make to Stock & 286 \\
\hline D & Consumer goods & Make to Stock & 568 \\
\hline E & Consumer goods & Make to Stock & 238 \\
\hline F & Consumer goods & Make to Stock & 236 \\
\hline G & Consumer goods & Make to Stock & 100 \\
\hline H & Foods and Beverages & Make to Stock & 310 \\
\hline I & Minning & Make to Stock & 119 \\
\hline J & Pulp and paper & Make to Stock & 83 \\
\hline K & Telecom & Make to Stock & 8,548 \\
\hline L & Textiles & Make to Stock & 17 \\
\hline M & Tools & Make to Stock & 48 \\
\hline N & Transportation equipment & Make-to-order & 714 \\
\hline O & Whosale & Make to Stock & 60 \\
\hline Soure & & & \\
\hline
\end{tabular}

Source: the authors themselves.

\subsubsection{Inputs}

Sales forecast, supply plans, inventory position, new product launch information, trade promotions, updated calculated costs, prices and budget figures are the main S\&OP process inputs.

Even though most of the transactional data comes from the ERP system, none of the researched companies uses it directly as the main source of information to execute the S\&OP process. The most common used information technology (IT) tool to support the S\&OP process are spreadsheets in eleven companies (73\%). As a consequence, Data Gathering step depends on spreadsheets, which requires a strong discipline from the business functions responsible for updating and keeping them accurate. Five companies (33\%) have S\&OP systems to manage the process but it is also a source of historical data, among others.

Five companies (33\%) informed that one of their biggest challenges is obtaining reliable information to manage the portfolio and to plan the inventory (e.g., new product launch schedule, production readiness, expected arrival dates of materials, mix changes by channel and planned phase-out date of obsolete product). All companies considered that increasing 
collaboration with key customers is a great opportunity, which needs to be pursued to improve the sales forecast and the service level. Two companies in this smaller group recognized that they need to improve the quality of the information available on portfolio management to leverage the Demand Planning step. According to Goh and Eldridge (2019), Strategic Alignment and Information Acquisition \& Processing are the two mechanisms that have the most positive impact to obtain S\&OP superior results.

\subsubsection{Structure and Processes}

The studied fifteen companies present different levels of maturity in their S\&OP process implementations. Eleven companies (73\%) have a formalized process with stablished calendar and agenda; clear roles and responsibilities and defined S\&OP team. The remaining four companies have processes running periodically but present serious issues such as: the meeting calendar changes frequently, the S\&OP team is not defined or some people are not committed, people miss some meetings because they have other priorities, the procedures are not completely standardized and deployed, top managers do not sponsor the process.

All investigated companies considered that finance should play a more active role in the S\&OP process. Finance could add more value by building and discussing what-if scenarios and supporting the decision making process, contributing to resolve trade-off situations. With the exception of company ' $I$ ', fourteen organizations indicated that the participation of finance is focused on presenting the actual results against budget. Five respondents in managerial positions (companies A, C, E, G, and H) stated that the lack of software capability to perform simulations and inadequate KPIs (and ways to measure them properly) are some of the main causes of finance's weak participation. Other two respondents (companies $E$ and $N$ ) mentioned the lack of clear definition of the role of finance in the process and the perception that S\&OP is about balancing demand and supply, thus involving mostly sales and operations. However, finance should play a key role in the S\&OP cycle (Viswanathan, 2009; Noroozi and Wikner, 2017; Oliver Wight, 2018) as companies can integrate budgeting and financial planning in their process (Baumann, 2010; Thomé et al., 2012a; Noroozi and Wikner, 2017) to assess investments, costs, revenue and profit thus improving the decision-making process (Noroozi and Wikner, 2017).

Eight companies (53\%) include portfolio management discussions formally in the S\&OP process. Three (20\%) of them (D, G and J), which manufacture and commercialize consumer goods, have marketing in a leading role, defining new product launches, portfolio by channel, demand scenarios for new products and product phase-out. In the remaining seven companies (47\%), these discussions are held in parallel with the S\&OP cycle, within marketing and sales, and the definitions are communicated as process inputs. Lack of information or information arriving late or decisions that did not consider supply capabilities and lead times happen from time to time. Because of these issues, in this group, six companies (40\%) consider that having more portfolio management discussions during the S\&OP cycle adds value to the decision-making process. It is a gap that needs to be addressed.

Regarding KPI's, all companies have financial metrics and compare budget with actual results (e.g., costs and revenues) but none of them discusses the margins within the context of the S\&OP process. This is an improvement opportunity as the margins may be impacted by causes that could be discussed within the S\&OP cycle (e.g., logistics costs impacted by urgent or small orders, manufacturing costs impacted by overtime, excess of inventory). A low forecast accuracy may have a great negative impact on the costs and margins. Only six companies (40\%) have a KPI implemented to measure forecast error (Minimum Absolute Percentage Error - MAPE) or forecast accuracy (Sales Forecast Accuracy - SFA). Interesting to note that five $(D, G, H, J, N)$ out of the six companies that measure MAPE/SFA are focused on the mass market. The fifteen companies have inventory metrics but the information is analyzed at the aggregate level only. That is another improvement opportunity as the cycle meetings are a great forum to evaluate and resolve excess and obsolete inventory issues. 
Delivery reliability KPIs such as Fill Rate (FR) or On Time in Full (OTIF) are common metrics in all fifteen companies, while the delivery cycle time is measured and analyzed only in three (20\%). Conflicts among KPI's (e.g. inventory level vs. capacity allocation, fill rate vs. on time) are usually discussed for the short term (next weeks) and based on practical experience. In line with Gomes et al. (2004), it is necessary to measure performance properly otherwise any initiative to implement best practices will not succeed.

From an IT stand point, only five companies (33\%) (B, D, F, J and N) use a dedicated S\&OP software to enable the process. The other 10 companies (67\%) rely on several spreadsheets and listed their difficulties such as simulation of different scenarios, collaboration among the business functions, reliable KPI calculation (e.g., MAPE, SFA, service level), data security and management, among others. Four out of the six companies that measure forecast error use the dedicated S\&OP software to perform this calculation. The S\&OP software is also a tool to plan the demand based on mathematical forecast and inputs from sales and marketing. The five companies decided to implement a specialized S\&OP software only after assessing their ERP system's capabilities and adherence to their process requirements. Although ERP systems have the advantage to be the central repository for most of the transactional data required for this process, they do not provide in their standard versions a process oriented approach neither capabilities to support practices like collaboration and portfolio management. It is important to mention that the 15 companies use recognized ERP systems in the Brazilian market.

\subsubsection{Outcomes and Results}

The S\&OP process implemented in the companies generates initially an unrestricted demand plan, then a supply plan with constraints is produced and finally the reconciled consensus-based demand plan and supply plan, with identified gaps, the possible gap mitigation action plans and the financial analysis. The main goals are achieved but the quality of the information varies. For instance, companies that do not use a dedicated S\&OP system get from this process gross demand at SKU level to feed their ERP systems. Three companies (20\%) (D, F and J) that use a dedicated S\&OP system determine net demand as input for their ERP system (inventory on hands and in-transit are taken in account). All fifteen companies state that they do not perform trade-off analysis adequately for a tactical time frame.

\subsection{Companies' S\&OP cycle-steps compared to Wallace and Stahl (2006) model}

The second framework used as a reference to assess the companies' S\&OP implementations is the five-step model proposed by Wallace and Stahl (2006). This research identified that the eight companies (53\%) that have a formal standard process in place consider step 1 as "Portfolio Management" instead of "Data Gathering". This finding shows that some current business practices are challenging the original model regarding the first step. Respondents from four companies ( $B, D, F$ and $N$ ) expressed that portfolio management have gain importance in the process due to shorter products life cycle and new market opportunities identified by the organization. In order to keep demand and supply manageable from a tactical stand point, this function became a key element to drive decision and plans regarding demand estimation for new products, launch readiness, rampup plans, phase-out plans, replacements, coordination of trade marketing, logistics and channels etc.

Table 3 presents how the companies assess themselves in a scale from 1 to 3 (weak, regular, well executed) from a process maturity perspective. The respondents from each company gave grades for each step of their S\&OP process. Steps 2 and 3 present a higher maturity level (average of 2.5 and 2.7 respectively of a maximum of 3.0). Steps 1, 4 and 5 show a much lower score (average 1.5 of a maximum of 3.0). 
Table 3. S\&OP steps maturity assessment

\begin{tabular}{lcccccc}
\hline & Industry & Step 1 & Step 2 & Step 3 & Step 4 & Step 5 \\
\hline A & Telecom & 1 & 3 & 2 & 1 & 2 \\
\hline B & Auto-parts & 1 & 3 & 3 & 2 & 1 \\
\hline C & Transportation equipment & 1 & 3 & 3 & 2 & 1 \\
\hline D & Consumer goods & 3 & 2 & 3 & 2 & 3 \\
\hline E & Agricultural machinery & 2 & 3 & 3 & 2 & 1 \\
\hline F & Consumer goods & 2 & 3 & 2 & 2 & 2 \\
\hline G & Consumer goods & 1 & 2 & 3 & 2 & 2 \\
\hline H & Foods and Beverages & 1 & 3 & 3 & 1 & 1 \\
\hline I & Mining & NA & 2 & 3 & 1 & 1 \\
\hline J & Consumer goods & 2 & 2 & 3 & 2 & 2 \\
K & Apparel and footwear industry & 1 & 2 & 2 & 1 & 1 \\
\hline L & Pulp and paper & 1 & 2 & 2 & 1 & 1 \\
\hline $\mathrm{M}$ & Textiles & 1 & 2 & 2 & 1 & 1 \\
\hline $\mathrm{N}$ & Wholesale & 3 & 3 & 3 & 2 & 2 \\
\hline $\mathrm{O}$ & Tools & 2.5 & 2.7 & 1.6 & 1.5 \\
\hline & & & 3 & 3 & 1 \\
\hline
\end{tabular}

Source: the authors themselves.

\subsection{Research key findings and lessons learned}

The research showed that steps 1, 4 and 5 from the Wallace and Stahl (2006) model are the major focus of improvement. By using the framework proposed by Thomé et al. (2012a), a second perspective is collected regarding elements with opportunities: inputs, structure and processes and outcomes are the ones with more opportunities to be improved.

Regarding inputs for the S\&OP process, most of the companies mentioned that they face challenges to gather the necessary transactional data from their ERP's systems and treat them in an appropriate format and level to support the five steps of their S\&OP process. For example, sales and marketing organizations need to view information for the collaboration forecasting process grouped by channel or by any criteria that makes sense from a sales perspective. Logistics and manufacturing need to see this same information by SKU, distribution center and production facility.

Eleven (73\%) out of the fifteen companies extract raw data from their ERP systems to feed spreadsheets that are used to support the S\&OP process separately. Three companies (20\%) mentioned that are using Business Intelligence (BI) platforms but the results are not good yet because each business function is building their own views. At this moment, the Bls are not enabling trade-off analysis or simulation of "what-if" scenarios. Four of the fifteen companies have adopted an S\&OP platform to enable the five steps approach being executed as a process capable to raise trade-offs and to perform 'what-if' analysis.

The four questions of the survey had the purpose of deepening the results of the interviews. It also helped to identify what type of initiatives and practices respondents believe that could leverage the maturity level of a particular step process of their S\&OP.

One of the key points addressed by the survey are the initiatives or enablers that could leverage the collaboration process inside the demand review phase (step 2). For the majority of the respondents, a good demand review process can't depend only on the usage of math 
forecasting techniques. For those products that are suitable for promotions, trade marketing campaigns, present price elasticity or are in the launch or phase-out phase, collaboration among marketing and sales is a key practice to improve demand accuracy. The first question of the survey was: "What feature/tool could improve and speed-up the collaboration process among trade marketing team, sales teams and sales representatives?" Most of the respondents for this question chose the option "simplified collaboration process (43\%). Interviewing once more some of the respondents to validate this option, they highlighted that a simplified collaboration process would encourage more engagement and does not open too much the range of options for the actor of the process. The second option with higher percentage (23\%) was "setting-up a scheduled time window" for each step of the S\&OP workflow. This feature would help to create discipline and control along the cycle of the S\&OP. Other two answers achieved the same percentage (13\%): gamification of the collaboration process thru some kind of reward model and insights based on data analytics techniques. Respondents from the consumer goods companies $\mathrm{D}$ and $\mathrm{F}$ expressed their belief that the usage of data analytics techniques could improve the collaboration process by providing insight of which products to offer and for which channels.

The second question of the survey addressed step four of the process regarding financial analysis and simulation capabilities, a common concern identified during the interviews. The question was: "Which aspects of the pre-SOP review could enhance the financial simulation enabling trade-off analysis and scenarios analysis"? Two major concerns raised with this question are inventory and cash analysis. From the total 30 respondents, 40\% indicated that being able to simulate in monetary values the projected inventory for different scenarios is key for the financial analysis. The second item in importance indicated by the respondents (30\%) was "develop capability to visualize and balance the trade-offs between fixed costs and logistics costs". It is important to note that the sample covered in this survey is mostly formed by industrial companies (exception is one wholesaler and one telecom company). The third aspect raised by this question with $17 \%$ was "capability to compare a baseline financial figure (i.e. budget) with different forecasted scenarios build during the steps 2 and 3". The main goal with this capability is to understand the major gaps between budget and "actual + forecast" in order to drive agreed actions to mitigate the causes. The last aspect identified by $13 \%$ of the respondents was "to develop the capability to estimate gross and net margins based on the demand and supply scenarios built in the previous steps ( 2 and 3$)^{\prime \prime}$.

The third question of the survey addressed step five of the S\&OP model and it was focused on data visualization for assessing scenarios and recommendations. The question addressed the low score achieved for step 5: "Which information could be added in order to improve the executive meeting dashboard by providing a better understanding of the decision making scenarios and KPI's?" Figure 2 presents the improvement opportunities identified in the executive Meeting.

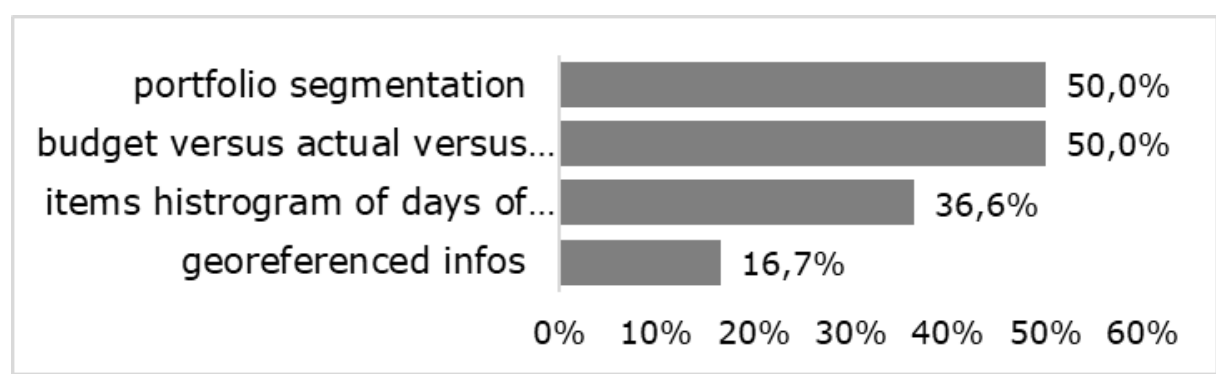

Figure 2. Opportunities in Executive Review KPI's Source: the authors themselves.

As shown by the results, provide better visualization of portfolio segmentation and more flexibility to assess financial results were the most frequent answers, with $50 \%$ of the respondents selecting these options. The third highlighted option was related with inventory 
profile (items histogram of days of supply) with $36.6 \%$ and the fourth was related with providing georeferenced information in the dashboard (16.7\%).

The fourth question was: "How could the effectiveness of events added in the collaborative process (like campaigns, trade marketing initiatives, promos etc.) be measured?" Three options were given for this question. The option "measure the level of engagement at execution level" represented $67.7 \%$ of the answers. The second option most chosen was "have some kind of enabler/feature to track events along the S\&OP cycle" with $29.0 \%$. The third chosen option was "possibility to input additional information regarding the events (e.g. attachments, pictures, notes etc.)" with 3.3\%. This last question raises the importance of the execution side of the S\&OP process, which could be deeper explored in future research.

\section{FINAL REMARKS AND CONCLUSIONS}

Interest in S\&OP has grown significantly in the last decades by practitioners and academics with an increasing literature body on the topic (Thomé et al., 2012a; Tuomikangas and Kaipia, 2014). Although, there is still a lack of empirical studies in the area offering many research opportunities and avenues for future research (Kjellsdotter Ivert et al. 2015a; Goh and Eldridge, 2015). This study aims to reduce this research-practice gap by providing for academics and practitioners relevant and useful information, not commonly found in other empirical studies. Many of the issues raised during the interviews and from the survey reflect managers real-life concerns and challenges associated with running successfully the S\&OP process.

All studied companies of this research experience a complex supply chain environment that can be described by context variables such as: number of SKUs, frequent new product launches and promotions, variety of suppliers spread in many countries, imports management, long lead times, number of customers spread in huge geographic areas, presence in multiple market channels, company size, significant cost and revenue values.

The proposed RQ1 (How can the S\&OP process be characterized?) and RQ2 (What challenges and improvement opportunities can be identified in its execution?) were addressed along section 4, using two recognized frameworks from the literature as guides, Thomé et al. (2012a) and Wallace and Stahl (2006). Besides the two frameworks, this paper applies a multiple-case study approach associated with a survey as research method. Some of the main results and findings of the study are detailed in the sequence.

As previously seen, for those companies that already have a formal S\&OP process, "Data Gathering" is no longer the step 1 as it is considered a normal task. "Portfolio Management" is now the step 1 of the cycle with the objective to leverage step 2's outcomes, particularly for the ones that have a collaborative workflow in place along sales and marketing teams. The research also showed improvement opportunities in the Pre-meeting and the Executive Meeting steps. For Pre-meeting and Executive Meeting steps, the simulation and analysis of different scenarios from a financial perspective is the most cited improvement opportunity. Only 33\% of the companies studied adopt an S\&OP software. The others 67\% run their S\&OP with spreadsheets over extracted data from their ERP's. As a consequence, they face limitations to integrate and share useful information among the business functional areas and also poor capability to perform what-if analysis over different scenarios. Regarding metrics this study raised that the measurement of forecast error (or accuracy) is still poorly adopted as a KPI. Most of the companies that measure it are the same that uses a S\&OP software as an enabler for the process (four of the six that measure uses S\&OP software).

Even though all the studied organizations are Brazilian, they are large and complex enterprises, some are subsidiaries of multinational corporations, similar to others from the same business segments in other countries and constitute a representative sample of companies that implement and are benefited by the S\&OP process. The commonalities with other companies in different contexts indicate that the results of the research are generalizable thus increasing the contribution of this research. 
The interviews and survey bring to attention several themes that could receive deeper investigation in future research like: Why most companies are replacing "Data Gathering"(is it a fully automated process now?) from the original five-step Wallace and Stahl's framework for "Portfolio Management"? Is it possible to correlate the lower score reached by steps 1, 4 and 5 with some level of weakness in the elements proposed by Thomé et al. (2012a)? How to improve financial and trade-off analysis on steps 4 and 5 ? How these companies will evolve regarding their maturity and application of S\&OP process in the future? Would the results found be different in other countries? These are a few recommendations for future research based on this empirical study.

\section{REFERENCES}

Baumann, F. (2010), "The shelf-connected supply chain: strategically linking CPFR with S\&OP at the executive level", Journal of Business Forecasting-Methods and Systems, Vol. 29, No. 4, pp. 21-8.

Bower, P. (2015), "S\&OP in the Service Industry", The Journal of Business Forecasting, Vol. 34, No. 2, pp. 4.

Cox, J.F. and Blackstone, J.H. (2002), APICS Dictionary, 10th ed., APICS., Alexandria, VA.

Danese, P., Molinaro, M. and Romano, P. (2017), "Managing evolutionary paths in Sales and Operations Planning: key dimensions and sequences of implementation", International Journal of Production Research, Vol. 56, No. 5, pp. 1-18.

Feng, Y., D'Amours, S. and Beauregard, R. (2008), "The value of sales and operations planning in oriented strand board industry with make-to-order manufacturing system: Cross functional integration under deterministic demand and spot market recourse", International Journal of Production Economics, Vol. 115, No. 1, pp. 189-209. http://dx.doi.org/10.1016/j.ijpe.2008.06.002.

Feng, Y., Martel, A., D'Amours, S. et al. (2013), "Coordinated contract decision in make-to-order manufacturing supply chain: a stochastic programming approach", Production and Operations Management, Vol. 22, No. 3, pp. 642-60. http://dx.doi.org/10.1111/j.1937-5956.2012.01385.x.GarcíaVillarreal, E., Bhamra, R. and Schoenheit, M. (2019), "Critical success factors of medical technology supply chains", Production Planning and Control, Vol. 30, No. 9, pp. 716-35. http://dx.doi.org/10.1080/09537287.2019.1572248.

Gil, A.C. (2008). Métodos e técnicas de pesquisa social, 6. ed. Editora Atlas SA, São Paulo.

Goh, S.H. and Eldridge, S. (2015), "New product introduction and supplier integration in sales and operations planning", International Journal of Physical Distribution \& Logistics Management, Vol. 45, No. 9/10, pp. 861-86. http://dx.doi.org/10.1108/IJPDLM-08-2014-0215.

Goh, S.H. and Eldridge, S. (2019), "Sales and Operations Planning: The effect of coordination mechanisms on supply chain performance", International Journal of Production Economics, Vol. 214, pp. 80-94. http://dx.doi.org/10.1016/j.ijpe.2019.03.027.

Gomes, C.F., Yasin, M.M. and Lisboa, J.V. (2004), "A literature review of manufacturing performance measures and measurement in an organizational context: a framework and direction for future research", Journal of Manufacturing Technology Management, Vol. 15, No. 6, pp. 511-30. http://dx.doi.org/10.1108/17410380410547906.

Grimson, J.A. and Pyke, D.F. (2007), "Sales and operations planning: an exploratory study and framework", International Journal of Logistics Management, Vol. 18, No. 3, pp. 322-46. http://dx.doi.org/10.1108/09574090710835093.Ivert, L.K., Dukovska-Popovska, I., Fredriksson, A. et al. (2015b), "Contingency between S\&OP design and planning environment", International Journal of Physical Distribution \& Logistics Management, Vol. 45, No. 8, pp. 747-73. http://dx.doi.org/10.1108/IJPDLM-04-2014-0088.

Kjellsdotter Ivert, L.K., Dukovska-Popovska, I., Kaipia, R. et al. (2015a), "Sales and operations planning: responding to the needs of industrial food producers", Production Planning and Control, Vol. 26, No. 4, pp. 280-95.

Kathuria, R., Joshi, M.P. and Porth, S.J. (2007), "Organizational Alignment and performance: past, present and future", Management Decision, Vol. 45, No. 3, pp. 503-17. http://dx.doi.org/10.1108/00251740710745106. 
Kristensen, J. and Jonsson, P. (2018), "Context-based sales and operations planning (S\&OP) research: A literature review and future agenda", International Journal of Physical Distribution \& Logistics Management, Vol. 48, No. 1, pp. 19-46. http://dx.doi.org/10.1108/IJPDLM-11-2017-0352.

Lapide, L. (2004a), "Sales and operations planning Part I: The process", The Journal of Business Forecasting, Vol. 23, No. 3, pp. 17-19.

Lapide, L. (2004b), "Sales and operations planning Part III: A diagnostic model". The Journal of Business Forecasting. Vol. 24, No. 1, pp. 13-15.

Lapide, L. (2011), S\&OP: The Linchpin Planning Process. The Journal of Business Forecasting. Vol. 30, No. 3, pp. pp. 18-20.

Noroozi, S. and Wikner, J. (2017), "Sales and operations planning in the process industry: A literature review", International Journal of Production Economics, Vol. 188, pp. 139-55. http://dx.doi.org/10.1016/j.ijpe.2017.03.006.

Oliver Wight (2018), Successful S\&OP through Integrated Business Planning. Oliver Wight EAME, Gloucester. available at: https://www.oliverwighteame.com/library/download/www/White\%20Papers/PDFs/Oliver\%20Wight\%20IBP_SOP_locked.pdf (accessed 10 February, 2020).

Pedroso, C.B., da Silva, A.L. and Tate, W.L. (2016), "Sales and Operations Planning (S\&OP): Insights from a multi-case study of Brazilian organizations", International Journal of Production Economics, Vol. 182, pp. 213-29. http://dx.doi.org/10.1016/j.ijpe.2016.08.035.

Scavarda, L.F., Hellingrath, B., Kreuter, T., Thomé, A.M.T., Seeling, M.X., Fischer, J.H., and Mello, R. (2017), "A case method for Sales and Operations Planning: a learning experience from Germany", Production, Vol.27, No. Spe, pp. 1-17. http://dx.doi.org/10.1590/0103-6513.219916

Seeling, M.X., Scavarda, L.F. and Thomé, A.M.T. (2019), "A sales and operations planning application in the Brazilian subsidiary of a multinational chemical company", Brazilian Journal of Operations \& Production Management, Vol. 16, No. 3, pp. 424-35. http://dx.doi.org/10.14488/BJOPM.2019.v16.n3.a6.

Thomé, A.M.T., Scavarda, L.F., Fernandez, N.S. et al. (2012a), "Sales and Operations Planning: A research synthesis", International Journal of Production Economics, Vol. 138, No. 1, pp. 1-13. http://dx.doi.org/10.1016/j.ijpe.2011.11.027.

Thomé, A.M.T., Scavarda, L.F., Fernandez, N.S. et al. (2012b), "Sales and Operations Planning and the firm performance", International Journal of Productivity and Performance Management, Vol. 61, No. 4, pp. 359-81. http://dx.doi.org/10.1108/17410401211212643.

Thomé, A.M.T., Souza, R.S. and Scavarda, L.F. (2014a), "The impact of sales and operations planning practices on manufacturing operational performance", International Journal of Production Research, Vol. 52, No. 2, pp. 2108-21. http://dx.doi.org/10.1080/00207543.2013.853889.

Thomé, A.M.T., Souza, R.S. and Scavarda, L.F. (2014b), "Complexity as contingency in Sales and Operations Planning", Industrial Management \& Data Systems, Vol. 114, No. 5, pp. 678-95. http://dx.doi.org/10.1108/IMDS-10-2013-0448.

Tuomikangas, N. and Kaipia, R. (2014), "A coordination framework for sales and operations planning (S\&OP): Synthesis from the literature", International Journal of Production Economics, Vol. 154, No. August, pp. 243-62. http://dx.doi.org/10.1016/j.ijpe.2014.04.026.

Viswanathan, N. (2009), Sales and Operations Planning: Integrate with finance and improve revenue. Aberdeen Group. Boston, MA.

Wallace, T.F. and Stahl, R.A. (2006), Sales and Operations Planning the executive's guide. T. F. Wallace and Company

Wang, J.Z., Hsieh, S.T. and Hsu, P.Y. (2012), "Advanced sales and operations planning framework in a company supply chain", International Journal of Computer Integrated Manufacturing, Vol. 25, No. 3, pp. 248-62. http://dx.doi.org/10.1080/0951192X.2011.629683.

Yin, R.K. (2009), Case Study Research: Design and methods, 4th ed., Sage Publications, Thousand Oaks, CA.

Author contributions: All the authors contributed equally to this paper. 


\section{APPENDIX 1 - INTERVIEW PROTOCOL}

The interviews performed during the research followed a protocol:

i) interviewer introduces himself and explained the purpose of the research;

ii) interviewee introduces himself (name, career, function);

iii) a semi-structured questionnaire designed for the research is applied to guide the interviews

iv) open-ended questions may complement the questionnaire to expand and clarify the information obtained;

v) interview closure and acknowledgements.

Favor adicionar a seguinte nota explicativa no rodapé da primeira página do artigo: 